\title{
NIETZSCHE NA POESIA DE WALY SALOMÃO
}

Flávio L. T. S. Boaventura

Centro Federal de Educação Tecnológica de Minas Gerais CEFET-MG. Professor do Programa de Pós-Graduação em Estudos de Linguagens.

\begin{abstract}
0
poeta Waly Salomão (1943-2003) manteve, sabidamente, forte ligação com o que há de mais essencial do pensamento trágico nietzschiano. Poeta de múltiplas polinizações e linguagens, além de demolidor incansável de fronteiras, Waly adorava baralhar antigas categorias estéticas. Impulsionada por "câmara de ecos e algaravias", sua poesia transitou por vários léxicos como se estivesse palmilhando diferentes estratégias de fundir a escrita com a plasticidade da vida, e vice-versa. Portadora de um "espírito dionisíaco", sua produção mescla metáforas, sentenças, parábolas, chistes, aforismos e não cede espaço para nenhuma verdade dogmática. Ao contrário. Afeito ao pensamento enviesado, de cunho antimetafísico, Salomão sempre foi um poeta entusiasmado pela multilinguagem e combateu ferozmente a monotonia do cânone. "Amante da algazarra e gigolô de bibelôs", sua obra demonstra ser, a um só tempo, repulsa do espírito fatigado e paixão incondicional pela alegria.
\end{abstract}

Palavras-chave: Waly Salomão. Nietzsche. Alegria. Trágico.

O que define o trágico é a alegria do múltiplo, a alegria plural.

(Gilles Deleuze, 1976, p. 14)

A poesia de Waly Salomão (1943-2003), sabidamente ambivalente e mutante, não comporta certezas nem tampouco admite generalidades convencionais: "o diabo faz seu ninho/ é nos galhos/ dos detalhes” (SALOMÃO, 2000, p. 19).

Rechaçar todas as categorias que comportem um geral e/ou um universal funciona, em Waly, como um irresistível dispositivo para forjar certa vontade de enganar. Demolidas as estruturas filosófico-metafísicas (dicotômicas), cabe ao poeta rivalizar com todo ideal ascético, não mais despendendo esforços com 


\section{ademens \\ ESPUC \\ BELO HORIZONTE - N. 28 - 2016}

\section{Flävio L. T. S. Bonventura}

"verdades infalíveis". Resta ao poeta, portanto, reconhecer no disfarce (máscara, duplo) o poderio do falso. É nesse sentido, a meu ver, que a poética de Waly instala sua usina de provocação: curto-circuito de potências efêmeras que afirmam novas possibilidades de vida. Afinal,

\section{o mistério continua, o fundo abissal das coisas não é suprimido (...) em hipótese alguma, mas o poeta continua em uma busca tonta, então, tem sido demente, mas tem que continuar, pois outro caminho não há" (SALOMÃO, 2005, p. 143).}

Não será demais lembrar aqui a importante distinção que Nietzsche (1998) faz entre o sofrimento inerente à vida e a falta de sentido do sofrimento assumido como maldição. De acordo com o filósofo, o que torna o sofrimento intolerável para a humanidade é a falta de sentido, e não a violência da dor, sua aparência de impotência diante do acaso da vida. (NIETTZSCHE, 1998, p.57-58). É nesse sentido que o poeta cultiva aparências, "aporta ao lugar do simulacro, o poeta feito máscara, persona em que o oco dobra e multiplica a voz do outro em timbre próprio e impróprio, espaço impreenchível em que escrever é vingar-se da perda." (ARRIGUCCI JR., 1996).

A contradição entre ideal e real - que gera uma revolta contra as condições "naturais" da vida - traduz, de acordo com Nietzsche, uma experiência de impotência ou doença. O indivíduo que se sente capaz de querer o que é não procura respostas "atrás das estrelas": ele afirma o devir (sempre mutável), tece figurações em torno da morte (percebe-se mortal, parte integrante da natureza) e livra-se de todas as "certezas", tornando-se amante do falso.

Com isso o poeta aguça a potencialidade da linguagem e a criatividade de sua elaboração, seja celebrando a falta e o vazio, seja zombando da experiência da morte sem morrer:

Mas a ira é bagagem do criador. Quem cria tem ímpetos de destruir quando a criação fica impertinente. E eu enquanto criador não difiro neste pormenor do lote dos demais criadores. Inventar criaturas diáfanas foi este o truque que me coube para driblar o caos ameaçador, a minha forma de assentar colônia na selva selvagem. Colônia? Como o senhor logo percebe ainda estou longe de conseguir encolher meu hiperbolismo pois só com muita boa vontade meu território passaria no registro como uma parca clareira. Meu pangaré é meu 
reino. Sou um demiurgo barato mas esperto quanto à intuição essencial: somente a crueldade nos transveste em similares dos deuses (SALOMÃO, 2005, p. 102103).

Afirmar o que é implica agir na contramão de qualquer Ideal, significa não cativá-lo. Todas as tentativas de descartar essa aceitação e reduzi-la a uma detestável forma de "tolerância" devem ser de antemão abolidas. O desafio nietzschiano do trágico dizer sim, retomado por Rosset para descrever seu princípio de realidade suficiente, recai sobre a poética dionisíaca de Salomão na medida em que, para o poeta, poesia é trabalho árduo de interação com o mundo sensível, corruptível, falível.

Waly é o tipo de criador que recusa ideias prontas, idealizações e cristalizações preestabelecidas: "a poesia não salva nada nem ninguém, ela somente supre o buraco da perda das certezas" (SALOMÃO, 2005, p. 61). Celebrar o perecível e satisfazer-se no mundo sensível, sem cânones e generalizações. Isso pode exigir uma tarefa mais espinhosa e difícil, mas não menos estimulante: reverter o platonismo significa expulsar todo nãopoético: "Que a poesia nos desoprima” (SALOMÃO, 2005, p. $58)$.

Eis a ruptura total com todo projeto de se fazer de vítima. A natureza intrinsecamente trágica da realidade pode ser confirmada pelo "caráter insignificante e efêmero de toda coisa do mundo" (ROSSET, 2002, p. 17), ignorando todos os pedidos de apelo.

A poesia de Waly é produtora incondicional de metáforas, parábolas, aforismos e não cede espaço para nenhuma verdade dogmática. Detentora de gingado fluido e incerto, mostra-se entusiasmada pela diferença e é opositora ferrenha da mesmice.

Amante da algazarra, sua obra demonstra ser, a um só tempo, repulsa do espírito conformista e paixão incondicional pela gargalhada. Para quem sabe poder, assim e enfim, devolver a morte à vida:

Agora é todo dia ancorar a caravela na enseada Subir encosta acima até o cocoruto do pedregulho E tirar chinfra com uns bons balaços-balanços de linguagem (SALOMÃO, 2000, p. 39).

$\mathrm{O}$ confronto com os textos de Waly Salomão traz à tona o caráter ambivalente de sua produção, na qual o perspectivismo e experimentalismo estão, de certa forma, relacionados. 
Embaralhar todos os códigos, dissolver todas as fronteiras em busca de uma vacância nômade: essa parece ser uma proposta cara ao poeta. Escorregadio, afinal, ele está credenciado para experimentar a transversalidade das dicções poéticas.

Cabe também sublinhar o caráter experimental dos textos de Waly Salomão. Seus aforismos - modo muitas vezes por ele privilegiado - não são senão renovadas tentativas bem humoradas de refletir sobre algumas questões, já que possibilitam experimentos com o pensar: "Faça você mesmo seu microtabuleiro/ enquanto jogo linguístico" (SALOMÃO, 2000, p. 68).

Daí a importância do festivo, o desfile de máscaras que faz o seu carnaval de metáforas: nomadismos múltiplos, intensidades impregnadas de travessuras. Nesse sentido, vale lembrar que o caráter do trágico nietzschiano é, acima de tudo, alegre, exatamente porque ama o seu destino:

Minha fórmula para a grandeza no homem é amor fati: nada querer diferente, seja para trás, seja para a frente, seja em toda a eternidade. Não apenas suportar o necessário, menos ainda ocultá-lo - todo idealismo é mendacidade ante o necessário - mas amá-lo... (NIETZSCHE, 1995, p. 51).

Esta é a arte de transfigurar empecilhos em expedientes: afirmar alegremente acasos e necessidades, descartando conformismos, resignações e submissões passivas. Amor fati demanda vitalidade (ou "vitalismo", nos termos de Deleuze, 1976) para realizar uma multiplicidade de planos heterogêneos de existência; afirmação dionisíaca do que advém. De acordo com Nietzsche, aliás, não há maior afirmação dos diversos planos de existência do que a afirmação de tudo que retorna (tragicamente) sem cessar (Heráclito).

Não por acaso, a alegria é tematizada por Clément Rosset como expressão máxima de uma radical adesão ao viver (a vontade de potência de Nietzsche), cuja experiência esplendorosa consiste em exaltar, de maneira incondicional, a inafiançável transitoriedade da vida:

a alegria constitui a força por excelência, seja simplesmente por dispensar, precisamente, a esperança - a força maior em comparação com a qual toda esperança aparece como derrisória, substitutiva, equivalente a um sucedâneo e a um produto de substituição (ROSSET, 2000, p. 29). 
Nesse sentido pode-se dizer que o aforismo é, à maneira de Nietzsche, alegre e risonho - ou será melhor dizer ridente? exatamente porque ele funciona como ferramenta de trabalho (máquina de guerra) contra as investidas político-religiosas do sério: através de seu caráter humorístico (irônico e sarcástico), podem-se revelar os dilemas de cada época. Aforismo enquanto desterritorialização, ou seja, agenciamento construído sobre linhas de fuga, forma enviesada de pensamento-acontecimento sem certezas demarcatórias.

\title{
NIETZSCHE IN WALY SALOMÃO'S
}

\section{POETRY}

\begin{abstract}
The poet Waly Salomão (1943-2003) maintained connection to what is more essential in the Nietzschean tragic thought. A poet of languages multiples, in addition to being a border breaker, Salomão loved shuffling old aesthetic categories. Driven by a "chamber of echoes and gibberish", his poetry moved through various lexicons as if treading through different strategies to merge writing with the plasticity of life. Carrying a "Dionysian spirit", his production mixes metaphors, sentences, parables, jokes, aphorisms and does not give room for any dogmatic truth. On the contrary, accustomed to biased thought of anti-metaphysical nature, Salomão was always a poet excited about multilanguage and fiercely fought against the monotony of the canon. Lover of hubbub and gigolo of bibelots, his work proves to be, at the same time, the repulse of the wearied spirit and an unconditional passion for joy.
\end{abstract}

Keywords: Waly Salomão. Nietzsche. Joy. Tragic.

REFERÊNCIAS

ARRIGUCCI JR, DAVI. In: SALOMÃO, Waly. Algaravias Câmara de ecos. Rio de Janeiro: Editora 34, 1996. 
DELEUZE, Gilles. Nietzsche e a filosofia. Tradução de Edmundo F. Dias e Ruth J. Dias. Rio de Janeiro: Editora Rio, 1976.

NIETZSCHE, Friedrich. Além do bem e do mal: prelúdio a uma filosofia do futuro. 2. ed. Tradução, notas e posfácio de Paulo César de Souza. São Paulo: Companhia das Letras, 1992.

NIETZSCHE, Friedrich. Ecce homo: como alguém se torna o que é. Tradução, notas e posfácio de Paulo César de Souza. São Paulo: Companhia das Letras, 1995.

NIETZSCHE, Friedrich. Genealogia da moral: uma polêmica. Tradução, notas e posfácio de Paulo César de Souza. São Paulo: Companhia das Letras, 1998.

ROSSET, Clément. Alegria: a força maior. Tradução de Eloisa Araújo Ribeiro. Rio de Janeiro: Relume Dumará, 2000.

ROSSET, Clément. O princípio de crueldade. 2. ed. rev. Tradução de José Thomaz Brum. Rio de Janeiro Rocco, 2002.

SALOMÃO, Waly. Armarinho de miudezas. Ed. rev. ampl. Rio de Janeiro: Rocco, 2005.

SALOMÃO, Waly. Tarifa de embarque. Rio de Janeiro: Rocco, 2000.

Recebido em: 25/06/2015

Aceito em: 05/11/2015 